\title{
TONSILLOLITH AS A CAUSE OF GLOSSOPHARYNGEAL NEURALGIA- AN UNUSUAL ENTITY
}

\author{
Sangeeta Aggarwal1, Barjinder Singh Sohal²
}

${ }_{1}^{1}$ Assistant Professor, Department of ENT, GMC and H, Patiala, Punjab, India.

2Senior Consultant, Department of ENT, Patiala Heart Institute, Patiala, Punjab, India.

HOW TO CITE THIS ARTICLE: Aggarwal S, Sohal BS. Tonsillolith as a cause of glossopharyngeal neuralgia- an unusual entity. J. Evolution Med. Dent. Sci. 2018;7(46):5055-5056, DOI: 10.14260/jemds/2018/1124

\section{PRESENTATION OF CASE}

A 36-year-old male presented in our outpatient department with the complaint of radiating pain on the right side of neck, lasting for few seconds. It was mainly in the throat on the right side and radiated to the ear off and on. He had been taking medical treatment from private practitioners in the form of painkillers, but got temporary relief. He was diagnosed as a case of GPN by an ENT specialist in a private institution and given Tegretol $200 \mathrm{mg}$ thrice a day and gabapentin alternately. This gave him relief, but the attacks were not fully controlled. He used to be depressed because the attacks of lancinating pain disturbed his sleep at night and in the morning left him drowsy and unable to perform his daily chores.

On detailed clinical examination he gave history of post nasal discharge, so to rule out sinusitis he was advised CT scan (Coronal View) of paranasal sinuses. It showed bilateral almost normal sinuses. The styloid process on the left side was elongated, but on the affected right side it was normal in length. Calcified foci were seen in both the palatine tonsils suggestive of tonsilloliths [Fig. 1].

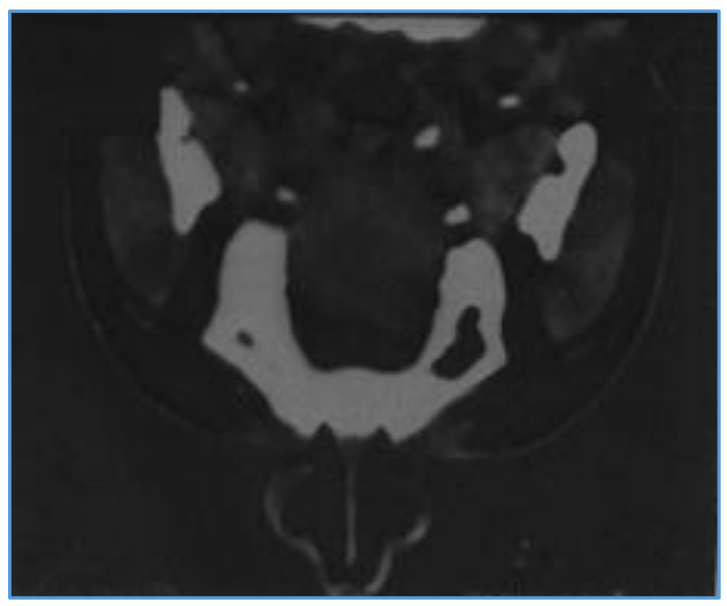

Figure 1. Coronal View of CT Scan PNS showing Calcified Foci in both Palatine Tonsils

For confirmation of GPN, the patient was given Injection Lignocaine as GP Block along the course of the $9^{\text {th }}$ nerve twice at weekly intervals and each time he had relief for a few days. This confirmed the diagnosis of GPN. It could not be related to the elongated styloid process, which was seen on the left side.

'Financial or Other Competing Interest': None.

Submission 05-06-2018, Peer Review 29-10-2018,

Acceptance 05-11-2018, Published 12-11-2018.

Corresponding Author:

Dr. Sangeeta Aggarwal,

The Art of Living Centre,

147, Punjabi Bagh,

Patiala-147001, Punjab, India.

E-mail: aggarwalsangeetadr@gmail.com

DOI: $10.14260 /$ jemds/2018/1124

\section{(c) $(1) \ominus$}

Since Tonsillolith as a cause of GPN could not be found documented in literature, the patient was given counselling regarding tonsillectomy presuming that the tonsillolith may be an underlying cause.

The patient underwent bilateral tonsillar resection under general anaesthesia and histopathology report showed dystrophic calcification in both tonsils. The patient was followed up regularly for more than 5 months and his pain did not recur, nor did he require medication for relief of pain.

\section{CLINICAL DIAGNOSIS}

GPN resembles the much commoner condition of trigeminal neuralgia. The pain occurs in brief agonising stabs, which may be of great severity. They usually start in relation to the tonsil and radiate down the side of the neck, in front of the ear and to the back of the mandible. Very rarely the pain may begin deep in the ear. When the throat is the main site of pain some relief may be obtained by direct application of cocaine to lateral pharyngeal wall and posterior third of tongue. Carbamazepine given in increasing dosage upto $200 \mathrm{mg}$ four times daily may control the attacks and additional relief may be obtained with sedatives. If these measures prove unsuccessful, operation on the nerve may be necessary. The list of findings at surgical exploration includes a long styloid process, aberrant vessels coursing over the nerve, unsuspected neurofibroma and cholesteatoma (Howard D, 1997).[1]

\section{DIFFERENTIAL DIAGNOSES}

a. Atypical Trigeminal Neuralgia.

b. Stylalgia.

c. Eagle Syndrome/ Stylohyoid Syndrome.

d. Brain tumours.

\section{PATHOLOGICAL DISCUSSION}

Here, we present an unusual case of GP neuralgia where underlying cause was a giant tonsillolith and tonsillectomy on that side relieved the patient of his complaints.

In our case, Tonsillolith has been found to be the cause of Glossopharyngeal Neuralgia which has not been documented in literature.

Glossopharyngeal neuralgia, a rare disorder, usually begins after age 40 and occurs more often in men. Often, its cause is unknown. But sometimes glossopharyngeal neuralgia results from an abnormally positioned artery that compresses the glossopharyngeal nerve near where it exits the brain stem. Rarely, the cause is a tumour in the brain or neck. Glossopharyngeal neuralgia is distinguished from trigeminal neuralgia (which causes similar pain) based on the pain's location or results of a specific test. For the test, a doctor touches the back of the throat with a cotton-tipped applicator. If pain results, the doctor applies a local anaesthetic to the back of the throat. If the anaesthetic 
eliminates the pain, the glossopharyngeal neuralgia is diagnosed. Magnetic Resonance Imaging (MRI) is done to check for tumours.[2]

In 1921, Harris coined the term "glossopharyngeal neuralgia," describing it as a painful syndrome characterised by paroxysms of unilateral and severe lancinating pain occurring in the distribution of the nerve and which may be elicited by stimulation of trigger points in regions supplied by the nerve. Glossopharyngeal neuralgia usually occurs without any obvious cause. A thorough physical examination usually does not reveal any abnormality other than the identification of trigger points. Radiological examination including CT scans, MRIs and angiograms will be normal. In 1977, it became apparent that most of the cases of "idiopathic" glossopharyngeal neuralgia could be caused by vascular compression of the glossopharyngeal nerve at the nerve root entry zone, causing a hyperactive rhizopathy. The implicating vessel is usually the posterior inferior cerebellar artery (PICA), which frequently also compresses on the rootlets of the vagus nerve. The most important cause of a secondary glossopharyngeal neuralgia is the Eagle's syndrome due to either an elongated styloid process or calcification of the stylohyoid ligament. Cases of idiopathic neuralgia or Eagle's syndrome should be given a trial of anti-convulsant medical therapy with carbamazepine.[3]

Dr. Jho has developed minimally invasive endoscopic microvascular decompression surgery for GPN and neurovascular compression syndromes of other cranial nerves. This procedure consists of placement of small synthetic sponges between the compressing blood vessels and affected cranial nerves. It carries a good chance of relieving the symptoms associated with these disorders. ${ }^{[4]}$

The tonsilloliths are white or yellow coloured stones composed of calcium salts such as hydroxyapatite or calcium carbonate apatite, oxalates and other magnesium salts or containing ammonium radicals. The exact pathogenesis of these stones is unknown, although there are many hypotheses on the formation of these calculi. It has been stated that they originate as a result of repeated tonsillitis which lead to fibrosis of ducts of crypts and retention of epithelial debris thereof. This epithelial debris forms the ideal media for the growth of bacterial actinomyces and fungi such as Leptothrix buccalis. Finally, dystrophic calcification occurs as a result of deposition of above stated inorganic salts from the saliva secreted in the mouth by major and minor salivary glands. Tonsilloliths are rare in paediatric age group, as they occur between 20 and 77 years of age. These stones are usually found on X-ray or CT scan done for other reasons. Xray shows single or multiple radio-opaque shadows which can be mistaken for foreign body, calcified lymph node, unerupted tooth, calcified stylohyoid ligament or prominent tuber of maxilla or elongated styloid process. Computed tomography is found to be diagnostic by obtaining multiple axial sections.[5]

\section{DISCUSSION OF MANAGEMENT}

In the present case, the patient was not fully cured by medical treatment. The commonest cause of GPN elongated styloid process was also not present. A CT scan of the paranasal sinuses performed to see the condition of the sinuses. This incidentally detected the tonsilloliths in both tonsils. An elongated styloid process on the opposite side was asymptomatic. The tonsilloliths were present in the lateral mass of the tonsils; that is why they could not be felt on palpation or seen protruding in the oral cavity. The patient was explained about the procedure of tonsillectomy and it was also explained that tonsillectomy may or may not relieve his symptoms. The prognosis was explained and only then tonsillectomy was done. But to our pleasant surprise, the patient was completely cured of symptoms of GPN.

\section{FINAL DIAGNOSIS}

GPN, Tonsillolith.

\section{REFERENCES}

[1] Howard D. Neurological affections of the pharynx and larynx. Scott-Brown's Otolaryngology. Vo. 5. $6^{\text {th }}$ edn. 1997;5(9):5-6.

[2] Rubin M. Glossopharyngeal neuralgia. Merck Manuals 2007;Sec 6(96):1588.

[3] Soh KB. The glossopharyngeal nerve, glossopharyngeal neuralgia and the Eagle's syndrome - current concepts and management. Singapore Med J 1999;40(10):659-65.

[4] Jho HD. Glossopharyngeal neuralgia surgery: Dr. Jho's endoscopic microvascular decompression surgery. Glossopharyngeal Nerve Surgery 2011.

[5] Thakur JS, Minhas RS, Thakur A, et al. Giant tonsillolith causing odynophagia in a child: a rare case report. Cases Journal 2008;1(1):50. 